\title{
GÊNERO MULTIMODAL: A CAMPANHA PUBLICITÁRIA COMO FERRAMENTA ARGUMENTATIVA DE MÚLTIPLOS DISCURSOS CRÍTICOS
}

\begin{abstract}
Multimodal Genre: The publicity campaign as an argumentative tool of multiple critic discourses
\end{abstract}

\author{
Ariane Peixoto MENDONÇA (UEG) ${ }^{1}$
}

\begin{abstract}
RESUMO: No presente trabalho, propomos um estudo sobre o gênero campanha publicitária, cujo objetivo é utilizá-lo como instrumento para descrição, interpretação e problematização dos recursos semióticos utilizados como força da comunicação pela imagem. Busca compreender o indivíduo em suas relações com seus próprios desejos e motivações, ressaltando, assim, a necessidade cada vez mais urgente de um letramento multimodal para a compreensão e estudo dos mais diversos gêneros discursivos. Sob a luz da Análise de Discurso Crítica (RAMALHO \& RESENDE, 2011), por se tratar de uma abordagem científica interdisciplinar para estudos críticos da linguagem como prática social, além de uma visão sociointeracionista de linguagem, fundamentamos nossas análises na Teoria Multimodal da Semiótica Social, mais especificamente nos trabalhos de Kress (2011), Kress e Van Leeuwen (2001, 2006) e Joly (2007); nas concepções de texto de Koch (2002); nas teorias dos gêneros textuais de Bakhtin (2003) e de Marcuschi (2008). As múltiplas semioses desse gênero despertam o olhar para um novo perfil de leitura crítica que engloba não só recursos linguísticos, mas também aspectos contextuais, imagéticos e digitais, bem como a sua capacidade de argumentação. Partimos da perspectiva de gênero como "uma forma de ação social" (MILLER, 1994), como um "conjunto de enunciados relativamente estáveis" (BAKHTIN,2003), interativos, multimodalizados e historicamente situados, capazes de sofrer transmutações para atender às necessidades de interação social.
\end{abstract}

PALAVRAS CHAVE: Campanha Publicitária; Multimodalidade; Consumismo; Prática Social.

ABSTRACT: In the present article, we propose a systematic study about the publicity campaign genre, which objective is to utilize it as an instrument for description, interpretation and problematization of the semiotic resources used as communication force by the image. Analise e comprehends the individual in his relations with his own desires and motivations, emphasizing thus the evermore urgent necessity of a multimodal literacy for the understanding and study of more diverse discursive genres. Under the Critic Discourse Analysis (RAMALHO \& RESENDE, 2011, because it's about an interdisciplinary scientific approach for critic language studies as social practice, beyond a social-interactionistview of language, we base our analysis in the Social Semiotic Multimodal Theory, more specifically in the works of Kress (2011), Kress e Van Leeuwen (2001, 2006), and Joly (2007); in the textual conceptions of Koch (2002); in the textual genre theories of Bakhtin (2003) and Marcuschi (2008); The multiple semiosis of this genre awakens the look for a new critic reading profile that

\footnotetext{
${ }^{1}$ Mestranda do Programa de Pós-Graduação Interdisciplinar em Educação, Linguagem e Tecnologias (PPG IELT) - UEG- Campus CSEH . E-mail: arianeenglishteacher@gmail.com
} 
encompasses not only linguistic resources, but also its argumentative capacity. We start from the perspective of genre as "a form of social action" (MILLER, 1994), as a "set of relatively stable statements" (BAKHTIN,2003), interactive, multimodalized e historically situated, capable to suffer transmutations to attend the necessities of social interaction.

KEYWORDS: Publicity Campaign; Multimodality; Consumerism; Social Practice.

\section{INTRODUÇÃO}

O corpus escolhido para análise é parte dos arquivos compilados para corroborar com a pesquisa da dissertação de mestrado do Programa de Pós-Graduação Stricto Sensu Interdisciplinar em Educação, Linguagem e Tecnologias da Universidade Estadual de Goiás. Trata-se de uma proposta de se trabalhar com as perspectivas da Linguística Aplicada Crítica, vislumbrar a práxis em movimento e apresentar uma nova forma de ver o ensino e a aprendizagem de inglês. Dessa forma, percebe-se a necessidade de uma intervenção que não contemple apenas os conteúdos programáticos, mas a elaboração de um trabalho transgressor, oportunizando o direito do saber, do conhecer, do criticar e do mudar. Neste intuito, a Campanha Publicitária People In Need nos deu suporte para trabalhar os recursos semióticos e sob a luz da Análise de Discurso Crítica por se tratar de uma abordagem teórico e metodológica interdisciplinar para estudos críticos da linguagem como prática social. Acerca da sua interdisciplinaridade Ramalho e Resende nos afirmam que:

Sua característica interdisciplinar explica-se pelo "rompimento de fronteiras epistemológicas" com teorias sociais, pelo qual objetiva subsidiar sua própria abordagem sociodiscursiva assim como oferecer suporte para que pesquisas sociais contemplar, também, aspectos discursivos. Isso porque a linguagem se mostra um recurso capaz de ser usado tanto para estabelecer e sustentar relações de dominação quanto, ao contrário, para contestar e superar tais problemas (RAMALHO \& RESENDE, 2011 P. 13).

Na perspectiva da Análise do Discurso Crítica, a linguagem é parte irredutível da vida social, o que pressupõe "relação interna e dialética de linguagem - sociedade, em que questões sociais são, em parte, questões do discurso e vice-versa" (RAMALHO \& RESENDE, 2011 p. 12). Portanto, entendendo a linguagem como parte irredutível da vida social, a proposta desse estudo é de se trabalhar com as semioses para abarcar manifestações linguísticas tanto verbais quanto imagéticas bem como nas ações dos agentes sociais através dos múltiplos discursos críticos e da argumentatividade, isto é, pretende-se investigar a linguagem com base em textos, sem se atentar apenas para as 
REVISTA X, Curitiba, volume 14, n.3,211-226, 2019.

estruturações. Para isso, fundamentamos nossa análise na Teoria Multimodal da Semiótica Social, mais especificamente nos trabalhos de Kress (2010), Kress e Van Leeuwen (2001, 2006 e Joly (2007), através dos quais descrevemos e interpretamos os recursos semióticos utilizados na campanha People in Need ressaltando, assim, a necessidade cada vez mais urgente de um letramento multimodal para a compreensão e estudo dos mais diversos gêneros discursivos.

Consequentemente, justifica-se um trabalho baseado na Análise de Discurso Crítica como parte da prática social e o discurso é "central, pois aponta tanto para o sistema quanto para seu uso contextualizado" (RAMALHO \& RESENDE, 2011 p.14). Nesse viés, compreende-se o uso da linguagem como aportado em estruturas semióticas e sociais, sem perder de vista a flexibilidade dos eventos comunicativos, que possibilita a criatividade na produção de textos. A análise de discurso crítica sustenta-se como "aparato para a explanação de problemas sociais particulares quando defende que a linguagem mantém um tipo especial de relação com outros elementos sociais (FAIRCLOUGH, 2001).

Com este intuito, entende-se que problematizar e observar com mais profundidade como os temas classe, raça, gênero, sexualidade, dentre outros corroboram com as possibilidades de transgressão, conscientização e questionamento das práticas dominantes de leitura e escrita, elegemos por trabalhar com a campanha publicitária People in Need ${ }^{2}$.

\section{ANÁLISE DO CONTEXTO}

Trata-se de uma campanha publicitária produzida a pedido da ONG Cordaid, intitulada People in Need e realizada pela agência Saatchi \& Saatchi na Holanda. Com a intenção de situar as quatro figuras que compõem a campanha publicitária pela representatividade social que lhes dá visibilidade, inicialmente descrevemos o contexto no qual a campanha se insere, por meio da consulta a documentos institucionais dos anunciantes para, em seguida, desenvolvermos a análise propriamente dita. Com

\footnotetext{
${ }^{2}$ A campanha foi criada pela agência holandesa Saatchi \& Saatchi e integrou a lista dos vencedores no festival "Cannes Lions 2007", na categoria de "Outdoors/Fundraising \& Appeals". O festival foi criado em 1953 pela SAWA (Screen Advertising Worlds Agencies), sendo realizado na cidade de Cannes, na Riviera Francesa. Atualmente, é considerado o mais importante prêmio da publicidade mundial, de tal forma que as campanhas premiadas possuem grande prestígio e são muito valorizadas no meio publicitário. Disponível em https://www.cordaid.org/en/news/story-behind-little-money-bigdifference/ Acesso em 08/02/2019
}

Tradução nossa. 
REVISTA X, Curitiba, volume 14, n.3,211-226, 2019.

atenção voltada em ajudar os grupos mais vulneráveis da sociedade, a ONG atua especialmente junto a adultos e crianças que enfrentam a discriminação e/ou exclusão social. Está presente em 36 países na África, Ásia e América Latina, contando com cerca de 400 funcionários. Apesar de ter sido lançada em 2007, as imagens ainda continuam nas mídias sociais. A intenção da campanha era especificamente chamar a atenção dos consumidores para o fato de que o dinheiro que gastamos com roupas, acessórios, bebidas tão facilmente em nossas vidas diárias poderia fazer uma grande diferença em relação às pessoas que vivem em áreas de desastre

\section{A PUBLICIDADE E O DISCURSO PUBLICITÁRIO}

Ao se observar os gêneros de uma campanha publicitária, pode-se perceber que ele, tentando ocultar sua faceta comercial, representa uma construção discursiva ideal de uma ideia, um produto e/ou serviço, em razão de constituir-se uma elaboração na qual entram em jogo diferentes olhares: o do produtor, do jornal, da revista, do site, do consumidor, etc., o que configura como uma encenação elaborada.

Em vista disso, Charaudeau (1983) caracteriza esse gênero como uma encenação que promove determinado produto e procura fazer com que o consumidor acredite que aquele corresponde a um elemento auxiliar na busca por determinado resultado, que não pode deixar de ser desejado pelo consumidor, e que, nessa mis-en-scène, pretende-se favorecer o fabricante do produto, muito mais do que o consumidor. Visto sob esse prisma da encenação, o anúncio é uma das modalidades de apresentação dos desejos forjados do consumidor no nível do prazer, da descontração, da alegria. Nesse ponto, catalisa o mundo dos desejos, da imaginação e das necessidades, apresentando aspectos da realidade; melhor dizendo, desenvolvendo uma versão da realidade.

Produzir textos publicitários requer o uso de estratégias peculiares que influenciam o comportamento do possível consumidor pela argumentação e expressividade. Essas suas particularidades tornam a comunicação altamente eficiente. Nessa perspectiva, o texto publicitário é, portanto, "uma escultura que se comunica no conjunto em que inicialmente o redator joga as ideias conforme as informações e depois o esculpe como se fosse uma obra de arte" (GONÇALVES,1998, p.42). Nessa mesma linha de pensamento, Verstergaad \& Schroder (2004) corroboram com Gonzales quando afirmam que o texto publicitário é uma forma de comunicação em massa, cujos objetivos são transmitir informações e incitar as pessoas a certos comportamentos e tem 
como características ser:

\begin{abstract}
a) uma unidade estruturada por signos verbais - linguísticos e não verbais imagens (ícones), símbolos; b) uma forma de comunicação pública, isto é, que se dirige, em sua grande maioria, ao público anônimo, não conhecido particularmente pelo anunciante; c) uma comunicação em um só sentido, pois o fabricante e o anunciante se dirigem a um público que não pode responder à comunicação emitida; nesse sentido, o discurso publicitário é autoritário, pois não há como o receptor do anúncio manifestar sua opinião sobre a mensagem recebida; d) uma comunicação de caráter informativo e persuasivo, destinada a divulgar ideias - fins ideológicos - ou venda de serviços ou produtos - fins comerciais (GONZALES,2003, p.14).
\end{abstract}

Além disso, o anúncio tem de convencer de que o produto vai satisfazer alguma necessidade - ou criar uma necessidade que até então não fora sentida. Não basta que o consumidor chegue a sentir necessidade do produto: o anúncio deve convencê-lo de que a marca anunciada tem certas qualidades que a tornam superior às similares (VESTERGAARD; SCHRODER, 2004, p. 71). Poderíamos, então, afirmar que o objetivo final de uma publicidade é, de fato, provocar uma ação no consumidor.

Segundo Sampaio (1997, p.179), os termos ou as expressões "textos publicitários", "anúncios", "publicidade", "propaganda", “campanha publicitária” são equivalentes ou sinônimos. Porém, cabe aqui salientar que cada gênero, especificamente, tem repropósitos ligados ao suporte em que está inserido. Procurando ressaltar a importância do suporte, valendo-se do exemplo "Paulo, te amo, me ligue o mais rápido que puder" (MARCUSCHI, 2008), evidencia que, em alguns casos complexos, o suporte determina a distinção que o gênero recebe. Assim, pontua Marcuschi (2008): escrito em folha de papel, sobre a mesa de trabalho de alguém, esse texto é um bilhete; registrado em secretária eletrônica é um recado; enviado pelos correios, escrito em formulário próprio, é um telegrama; expresso num outdoor pode ser uma declaração de amor. O conteúdo é o mesmo, porém, o gênero identificado com relação ao suporte difere em várias situações.

Muitas atividades humanas, inclusive a campanha publicitária, estão relacionadas ao uso da língua que se evidencia em forma de enunciados orais e escritos, dinâmicos ou não. Esses enunciados retratam práticas sociais, muitas vezes específicas, pelo seu conteúdo temático, seu "estilo" verbal (seleção de recursos lexicais, fraseológicos e gramaticais da língua), e, principalmente, sua composição organizacional (BAKHTIN, 2003). Assim, entendemos que a formulação e a compreensão de um enunciado precisam ser vistas sob uma perspectiva interativa e 
REVISTA X, Curitiba, volume 14, n.3,211-226, 2019.

contextualizada, e essa abordagem requer do pesquisador saberes e habilidades necessárias, visto que os sujeitos estão inseridos dentro de um contexto sócio histórico altamente ideológico que reflete na produção das propagandas e estas se materializam como resultado da criatividade e inovação humana.

\section{TEXTO E MULTIMODALIDADE}

Todos os aspectos de nossas vidas, incluindo nossas atividades diárias, profissionais e de aprendizagem são moldadas e transformadas pelas tecnologias digitais e os discursos que as permeiam. É inquestionável, portanto, o vasto potencial criador proporcionado pelos sites de redes sociais o que permite que os usuários experimentem diferentes formas de interação, indo, por vezes, muito além daquelas oferecidas pelos sistemas. Neste contexto, a manipulação de gêneros se faz presente e seu exercício satisfatório leva à produção de novos gêneros a partir do pensamento e reelaboração criadora. Por gêneros, entendemos a concepção proposta por Bakhtin (2003), como tipos relativamente estáveis de enunciados, elaborados em uma esfera social, caracterizados por tema, estilo e pela construção formal que os compõem e a valoração que os orienta.

Apropriar-se de um gênero é realizar efetivamente uma situação sociointerativa. É também uma forma de legitimar o pensamento, de posicionar-se diante de um fato, além de uma maneira, segundo Marcuschi (2006), de "controle social e exercício de poder”. O gênero está a serviço da comunicação. Dependendo da intenção discursiva dos interlocutores, eles escolhem um gênero específico, tudo depende da necessidade discursiva que pode ir de um simples recado, por meio de um bilhete, até um evento de controle social, por meio de um discurso político ou de um artigo de opinião. Para Bronckart (1999, apud Marcuschi, 2006, p. 154), "a apropriação dos gêneros é um mecanismo fundamental de socialização, de inserção prática nas atividades comunicativas humanas". Então, entender e conhecer os gêneros e suas particularidades, seu papel social e sua força histórica pode contribuir para ampliar a competência sociocomunicativa dos sujeitos.

Com o advento da pósmodernidade, e da era digital, diversas práticas e realizações sociais vêm sofrendo constantes modificações, o que tem reflexos na dinamicidade e na versatilidade das práticas linguísticas. $\mathrm{O}$ ambiente digital por sua vez, viabiliza diversas ferramentas para um público que aspira por materiais cada vez mais 
dinâmicos, ao mesmo tempo com conteúdo, e que são cada vez mais representações parciais do mundo.

\begin{abstract}
Com essas novas práticas de comunicação, novos letramentos surgiram. Eles estão incorporados nas novas práticas sociais - maneiras de se trabalhar em formas novas ou transformadas de emprego, novas formas de participar como cidadão nos espaços públicos e até mesmo talvez novas formas de identidade e personalidade (COPE, KALANTZIS, 2016).
\end{abstract}

Nessa perspectiva, os domínios digitais caracterizam-se pela presença de como também recursos imagéticos, objetos em movimento, sons, cores e disposições dos textos. Essa configuração ocorre devido à organização multimodal dos textos contemporâneos; a multimodalidade conduziu um novo olhar sobre o trato de questões linguísticas. Os diversos modos semióticos e sua dinamicidade convergem à criação de gêneros característicos do ambiente virtual, especialmente nas redes sociais, tais como o chat, tweet,posts,fanpages, fanclips, portais e memes. Isso se deve às novas ferramentas de leitura, produção e escrita permeados pela multiplicidade de modos de significar. $\mathrm{O}$ ambiente online é identificado, portanto, pela interatividade e pela grande possibilidade de produção cooperativa entre os usuários, tornando-se um meio catalizador de conceitos, principalmente devido à liberdade de acesso e participação coletiva (Moraes, Mendes e Lucarelli, 2011).

Essa atualidade é movimentada, ativa, dinâmica e impulsionada por mudanças em todos os aspectos, inclusive as sociais. Por isso, Predebon (2013) afirma que, em seu cotidiano, as pessoas criam, recriam, transformam, hibridizam saberes para suprir suas demandas interativas. Isso se faz presente quando acompanhamos as mudanças ocorridas nas diferentes gerações. Nelas, há a presença de diferentes linguagens e formas de pensamento. Influenciadas por fatores sociais, culturais, pessoais e psicológicos, propõem-se novos exercícios de criatividade no meio social.

Neste contexto, percebemos que as campanhas publicitárias multimodais fogem dos modelos mais conservadores e convencionais, a linguagem multimodal a argumentação, o conjunto das escolhas léxico-gramaticais e visuais nas campanhas expressam os objetivos e constroem uma visão da realidade, ajudando no comportamento criativo das pessoas, pois apresentam novas possibilidades de criação, leitura e releitura, por meio dos seus mais variados recursos.

A semiótica considera todos os signos e as diversas formas de apresentação e manifestação desses signos, de forma linguística ou não. A propaganda multimodal está 
REVISTA X, Curitiba, volume 14, n.3,211-226, 2019.

inserida em um contexto de multiformas, multilinguagens, multimídias, multissignos, multissentidos. Para Santaella (2007, p.29), a semiótica tem como função classificar e descrever todos os tipos de signos possíveis de forma lógica. Isso poderia caracterizá-la como de maior relevância sobre as outras ciências, uma vez serem todas constituídas de linguagens, signos a serem estudados na busca de uma razão.

Na visão de Rojo (2009), existem vários gêneros discursivos que exigem leitores aptos a entender as mais variadas formas de construção expressiva, os sentidos propositalmente formados. Os textos multimodais incorporam as modalidades de linguagem verbal (oral e escrita) e não verbal, e podem ser chamados de textos multissemióticos. Rojo ainda complementa que a multissemiótica ou a multimodalidade de linguagens explora um conjunto de signos/linguagens "exigidos pelos textos contemporâneos, ampliando a noção de letramentos para o campo da imagem, da música, das outras semioses que não somente a escrita" ROJO (2009, p.107).

\section{APORTE TEÓRICO METODOLÓGICO}

Neste artigo, realiza-se a análise qualitativa de uma campanha publicitária. A análise qualitativa, segundo Marconi e Lakatos (2011), possui suas características voltadas especialmente para descrição e análise dos dados, além de enfatizar seus significados. As autoras propõem que haja a correlação entre os dados da pesquisa e o seu quadro teórico. A seleção da campanha publicitária a ser analisada seguiu dois critérios: a) a publicidade impressa deveria inserir no contexto que oferecesse oportunidade de problematização e como poderia corroborar com as possibilidades de transgressão, conscientização e questionamento das práticas dominantes de leitura e escrita; b) o anúncio deveria apresentar elementos verbais e visuais proeminentes, ou seja, tanto palavras, como imagens afim de poder observar os textos em suas múltiplas faces: aspectos visuais e linguísticos, promovendo a percepção e o olhar crítico diante das possibilidades linguísticas dos textos.

A partir dessa perspectiva, associar a linguagem verbal e não verbal, bem como os elementos contextuais e os conhecimentos de mundo na busca da construção dos sentidos do texto, decifrando, dessa forma os implícitos e a intencionalidade da campanha publicitária. Essa perspectiva de análise baseia-se nas concepções de texto de Koch (2013), segundo a qual o texto é o próprio lugar da interação, em que os sentidos são construídos através das relações dialógicas entre os sujeitos. São as diversas vozes 
REVISTA X, Curitiba, volume 14, n.3,211-226, 2019.

presentes no discurso da propaganda que permitem essa interação entre os sujeitos dialogicamente construídos. Assim, foi escolhida a campanha publicitária People in Need, a pedido da ONG Cordaid.

\section{ANÁLISE DA CAMPANHA PUBLICITÁRIA PEOPLE IN NEED}

Com base nas metodologias da Análise da Imagem definidas por Joly (2007) e nas contribuições da Gramática Visual proposta por Kress e Van Leeuwen (2001), analisa-se a mensagem veiculada na campanha publicitária, conforme exemplares das figuras $1,2,3$ e 4 .

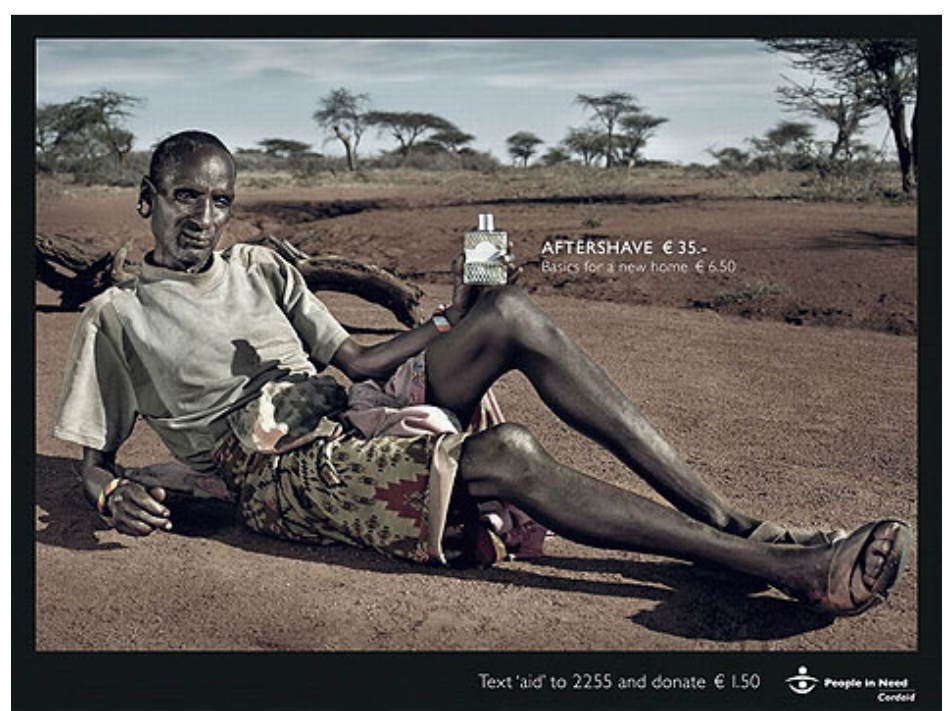

Figura 1 - People in Need - Site: http://theinspirationroom.com/daily/2008/cordaid-help-forpeople-in-need/ Texto: Loção pós-barba - 35 euros/Básicos de um novo lar - 6,50 euros

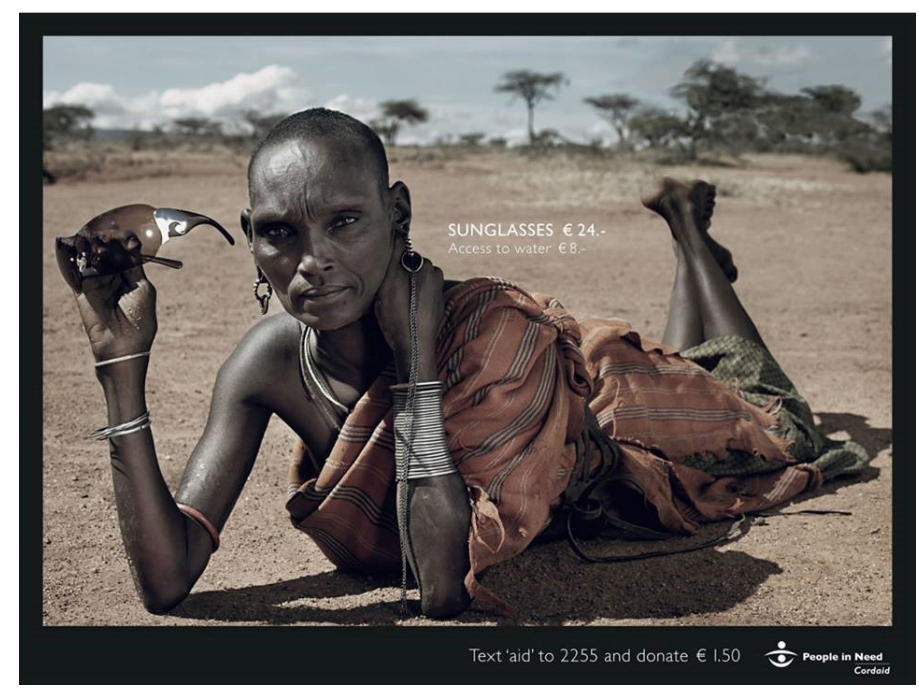

Figura 2 - People in Need - Site: http://theinspirationroom.com/daily/2008/cordaid-help-forpeople-in-need/: Óculos de sol - 24 euros/Acesso à água -8 euros 
REVISTA X, Curitiba, volume 14, n.3,211-226, 2019.

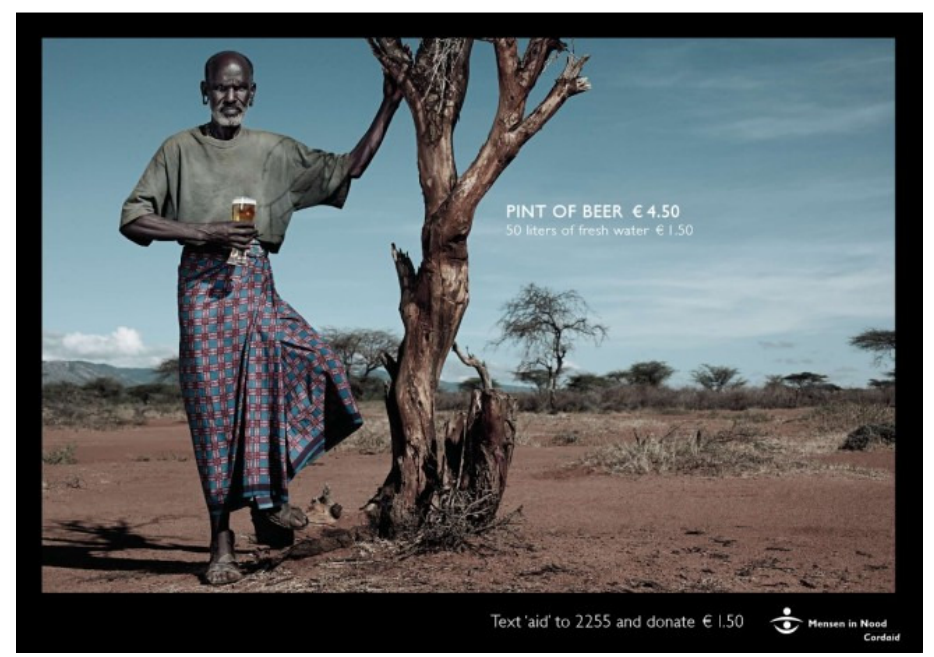

Figura 3 - People in Need - Site: http://theinspirationroom.com/daily/2008/cordaid-help-forpeople-in-need/ Texto: Tulipa de cerveja - 4,50 euros/50 litros de água fresca - 1,50 euros

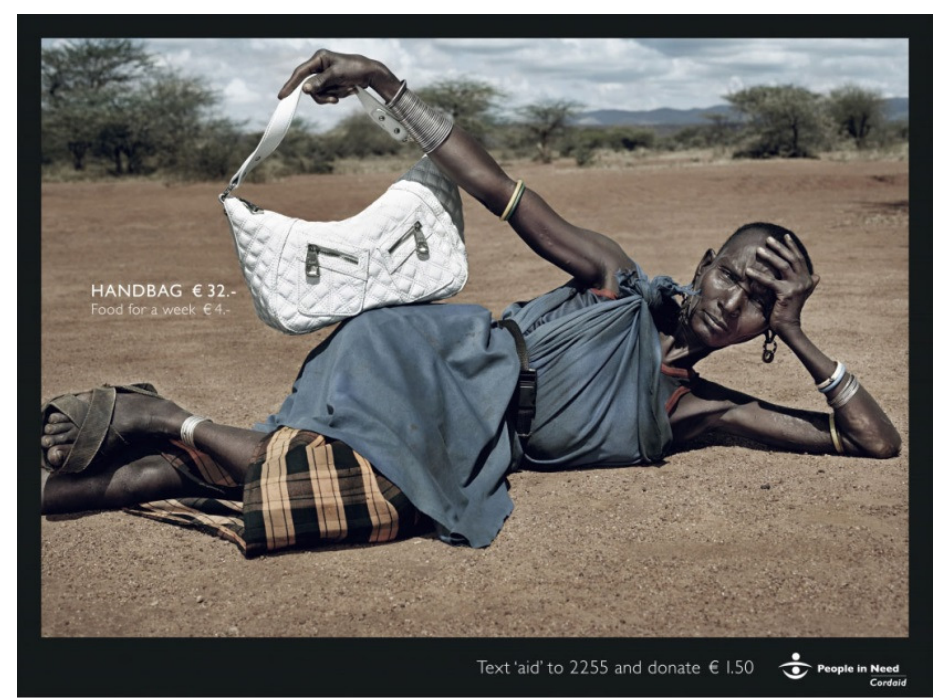

Figura 4 - People in Need - Site: http://theinspirationroom.com/daily/2008/cordaid-help-forpeople-in-need/ Texto: Bolsa - 32 euros/Comida para uma semana -4 euros

Entre os recursos visuais que compõem uma mensagem, figuram os signos plásticos. É fundamental revelar, de acordo com Joly (2007), que uma grande parte da significação da mensagem visual é determinada pelas escolhas plásticas. Na campanha, as imagens foram veiculadas em outdoors e revistas, e posteriormente em mídias sociais, razão essa pela qual as imagens ainda são lembradas por sua relevância em contexto. As imagens possuem molduras bem definidas, tanto explícita, levando em conta as bordas da imagem em cor preta, quanto implícitas, sem a interrupção da cena pelas bordas da imagem. No enquadramento dos objetos das fotografias, os/as modelos são visualizados/as de maneira integral, em "plano aberto", representando distanciamento. Do mesmo modo, a imagem constrói, no dizer de Aumont (1993, p.78), 
REVISTA X, Curitiba, volume 14, n.3,211-226, 2019.

uma vinculação com o domínio do simbólico, “[...] o que faz com que ela esteja em situação de mediação entre o espectador e a realidade". No entanto, trata-se de uma situação de comunicação monolocutiva com base em um canal pictórico, o que estabelece, de certo modo, um distanciamento do espectador com a obra. O participante representado exige do observador algum tipo de reação emocional imaginária (KRESS e van LEEUWEN, 2000).

Como, para Joly (2007), a escolha do ângulo é determinante, uma vez que reforça ou contradiz a impressão de realidade que está ligada ao suporte fotográfico, observamos que nas imagens o ângulo do olhar da objetiva é bem amplo, de um ponto de vista superior à posição do modelo, com a exceção da figura 3 , em que ela está em um ponto de vista inferior. As imagens são compostas pelos modelos, que são pessoas africanas deitadas ou, no caso da figura 3, em pé ao lado de uma árvore, posando em um ambiente de savana onde se observa o céu, algumas árvores, a grama seca e a terra. Essa representação reforça o estereótipo de que os países africanos são, apenas, uma grande floresta, um espaço ainda não modificado pela cultura e pela ação humana. Nas imagens há uma predominância de formas retas, com as curvas e arestas pouco pronunciadas, de acordo com a disposição dos elementos da cena. As imagens estão bastante iluminadas e com baixa saturação de cores.

Para Joly (2007), os ícones das imagens, para além do reconhecimento dos motivos, obtido graças ao respeito pelas regras de transformação representativa, existem para outra coisa diferente de si próprio, para as conotações que o rodeiam como satélites, ou seja, para as conotações que não estejam estritamente ligadas ao ícone. Assim, encontramos dois indicativos de motivos por todas as quatro figuras: a) primeiro é definido pela maioria dos elementos das cenas, remetendo a calor, a seca, à aridez e às savanas africanas; b) o segundo é definido pelos produtos portados pelos modelos, que remetem à vaidade, ao luxo e à opulência do estilo de vida das classes ricas das sociedades ocidentais. Observamos também as posturas dos/as modelos, que estão deitados ou em pé, com a disposição corporal de pose, que chama a atenção para o produto que seguram. Em todas as figuras os modelos olham diretamente para a objetiva, que implica o reconhecimento de que a imagem exige uma resposta do leitor (KRESS e Van LEEUWEN, 2000).

Ressalta-se também que a desigualdade social é um dos elementos que mais chamam a atenção nessa campanha publicitária. O corpo dos/as modelos nos revela os 
REVISTA X, Curitiba, volume 14, n.3,211-226, 2019.

traços sociais e históricos de uma sociedade como um todo, associados a isso aparecem a questão do cenário, das pessoas (modelos) e do próprio consumismo, pois é possível reconhecer que o contraste entre os valores dos produtos provoca a associação direta com a desigualdade social. Além disso, a campanha objetiva uma reflexão que enquanto uns possuem tão pouco, outros não se importam em esbanjar dinheiro e comprar bens de consumo supérfluos. Por isso, a campanha teve uma repercussão positiva nos suportes em que foi veiculada, tanto por chamar a atenção para a desigualdade social, principalmente na África, quanto por possuir um grande potencial para estimular mobilizações a favor de maior equidade entre classes sociais.

Com relação aos aspectos linguísticos, todas as figuras apresentam resumida informação textual. Em todas elas há, incluído no corpo da foto em sobreposição ao/a modelo (com a exceção da figura 3, localizado no espaço vazio da cena), duas linhas de texto, grafadas com uma fonte não-serifada ${ }^{3}$ de cor branca. A escolha dos caracteres é muito importante no implícito da mensagem. Essas duas linhas expõem o preço em euros dos produtos retratados (a loção pós-barba, os óculos de sol, a tulipa de cerveja e a bolsa de mão) e o valor equivalente do produto em termos de necessidades básicas do ser humano (material básico para uma casa, acesso a água, 50 litros de água potável, alimentação para uma semana), respectivamente. Observa-se que, nas linhas que descrevem os preços dos produtos, o texto está em caixa alta, enquanto nas linhas em que são descritos os direitos básicos, além de estarem em um tamanho menor, apenas a primeira letra da frase está em maiúsculo, criando sempre a impressão de que a segunda linha está em função complementar à primeira. Assim, o texto enfatiza um elemento dramático da imagem, que faz com que o interlocutor tenha sua atenção apreendida e se sinta compelido a ler o texto (KRESS e van LEEUWEN, 2000). Há também, na parte inferior direita da imagem, uma linha de texto na mesma fonte na qual encontramos o discurso imperativo característico da campanha publicitária, que busca agir sobre o observador da imagem (envie "ajuda" para 2255 e doe $€ 1,50$ ), junto com o símbolo e título da ONG responsável pela mesma. Como resultado deste tipo de configuração, um vínculo é estabelecido entre o participante representado e o interativo. A escolha do discurso imperativo é como se chamasse o participante para se sensibilizar com a

${ }^{3}$ Letras sansserif (fontes não-serifadas) não possuem serifas, como o nome sugere. O baixo contraste e a ausência de serifas torna os tipos sansserif mais difíceis de acompanhar em uma leitura típica. São bons para uma sentença, passáveis para um parágrafo, mas difíceis de usar efetivamente em, digamos, um texto de um livro. Disponível em:<http://www.graphic-design.com/typography/design/sans-serif-gothic-andgrotesque >. Acesso em 08/02/2019 "Tradução nossa". 
REVISTA X, Curitiba, volume 14, n.3,211-226, 2019.

nuance dramática da cena. Dessa forma, o texto enfatiza um elemento dramático da imagem, que faz com que o observador tenha sua atenção atingida e se sinta convencido a ler o texto (FERNANDES; ALMEIDA, 2008).

Para Koch (2002a), convencer conduz a certezas, sendo pertencente ao domínio da razão, voltado para um raciocínio estritamente lógico, e tentando convencer o interlocutor por meio de provas objetivas e de argumentos claros; persuadir busca atingir o interlocutor por meio dos sentimentos, da vontade, com argumentos ditos plausíveis ou verossímeis, e tem caráter ideológico, subjetivo, não criando certezas, mas sim buscando utilizar argumentos que podem levar a inferências (mas não verdades absolutas). Portanto, existem maneiras distintas para se compor uma argumentação: por meio da persuasão ou do convencimento, que, possivelmente, serão reguladas de acordo com a intenção do produtor, com o interlocutor e, especialmente com o texto do gênero de que ele se vale para expor seus argumentos. Nesse caminho, "as relações argumentativas dependem das intenções do falante (produtor) e são sustentadas pelo princípio da plausibilidade" (KOCH, 2002b, p. 121). Baseados nos conceitos de Martins (2008), é possível afirmar que a argumentação pode ser sustentada ou pela evidência, ou seja, com a apresentação de dados e fatos que fundamentam as qualidades do produto ou serviço no discurso publicitário; ou pela lógica, que se baseia na dialética tese, antítese e síntese (conclusão). Esse desencadeamento de proposições (premissas) permite que o leitor elabore um raciocínio, tirando suas próprias conclusões sobre, no caso da publicidade, o que está sendo promovido. Brown (1971, p. 5) afirma que:

\footnotetext{
O homem é um animal racional. Pelo menos é assim que ele gosta de considerar-se [...] O homem tem uma capacidade para raciocinar e ser influenciado. É interessante e significativo o fato de propagandistas religiosos e políticos, bem como publicitários, esforçarem-se como fazem para conceber argumentos (capciosos) dirigidos ao raciocínio.
}

Logo, a argumentatividade é dependente da intencionalidade, que está imbricada numa determinada relação, que pressupõe intencionalidade, pois, em todo e qualquer tipo de discurso, em maior ou menor grau, a argumentatividade está projetada em função das intenções discursivas em que se esteia o produto.

Neste contexto, ela se manifesta não só como a arte de persuadir pelo discurso, mas também assume um papel central nas sociedades de consumo pós-modernas, pois, diariamente, se é bombardeado por mensagens de caráter comercial, em que, para persuadir a consumir uma variedade de produtos e/ou serviços, utilizam-se estratégias 
REVISTA X, Curitiba, volume 14, n.3,211-226, 2019.

criativas e arranjos discursivos. E neste contexto, há também uma proposta persuasiva das necessidades conscientes e inconscientes que, mais ou menos, a compra satisfaz no consumidor segurança, narcisismo, identificação com uma classe social. Asseverando que a mais importante função da linguagem é argumentar, como afirma Marcuschi:

$\mathrm{O}$ ato linguístico fundamental é o ato de argumentar. Isto significa que comunicar não é agir na explicitude linguística e sim montar um discurso envolvendo as intenções em modos de dizer cuja ação discursiva se realiza nos diversos atos argumentativos construídos na tríade falar, dizer e mostrar (MARCUSCHI, 2002, p. 10).

A imagem publicitária, seguramente intencional e, portanto, essencialmente comunicativa e destinada a uma leitura pública, oferece-se então como o terreno privilegiado para a observação dos mecanismos de produção de sentido através da imagem.

\section{CONSIDERAÇÕES FINAIS}

Advindo das práticas sociais, o gênero textual campanha publicitária é reproduzido, desenvolvido e transformado, criando um mundo perfeito aos olhos do consumidor em potencial. Daí se percebe o papel importante que a construção multimodal ocupa na vida social e cultural da humanidade. Nesses termos, a seleção lexical, a escolha de uma forma verbal, o conjunto dos elementos plásticos e icônicos, o uso de modalizadores não é fruto do acaso, mas sim das prerrogativas argumentativas dessa esfera.

A campanha analisada mostra pessoas de origem africana, que vivem na linha da pobreza, posando com alguns itens que têm presença indispensável na sociedade de consumo e compara seus preços com os de algumas necessidades básicas e realmente imprescindíveis, como água e comida. A discrepância entre os valores nos faz refletir como gastamos dinheiro com coisas supérfluas enquanto muitas pessoas passam fome e sede. O consumidor poderia ajudar um africano a se alimentar por uma semana, a ter acesso a água potável e alimentação por exemplo.

Dessa forma, a ONG Cordaid trabalha com uma argumentação estruturante de todo e qualquer discurso e que nos possibilita dizer que ela figura como um dos componentes fundamentais de práticas discursivas cotidianas. Fazendo um comovente contraponto entre o consumismo exacerbado, e o fato de muitos não terem o suficiente sequer para necessidades básicas, a campanha da ONG Cordaid para o projeto People 
REVISTA X, Curitiba, volume 14, n.3,211-226, 2019.

in Need traz comoventes imagens impactantes, que chamam a atenção para questões como o real valor do dinheiro.

Assim, a proposta da campanha é a de que as pessoas reflitam a respeito do que realmente é necessário em um contexto no qual grande parte dos indivíduos está imersa em uma sociedade em que o consumo se faz diariamente presente. Nesse caso, os anúncios carregam um forte teor ideológico que busca gerar a reflexão por meio da percepção de que certos bens materiais não devem ser mais relevantes do que a ajuda ao próximo, em especial aqueles que nada possuem. Por fim, conclui-se que as ações realizadas a partir da campanha publicitária, tal como a People in Need, tem em si um potencial de transformação social, mesmo que sejam ações isoladas, a reflexão que propõe viabiliza aos mais diversos grupos deparar-se com questões sociais que merecem ser desveladas, considerando-se ainda que precisam sair do espaço de inércia a que são submetidos por ação do sistema hegemônico.

\section{REFERÊNCIAS}

ALMEIDA, D. B. L. de (Org.). Perspectivas em análise visual: do fotojornalismo ao blog. João Pessoa: Editora da UFPB, 2008.

AUMONT, Jacques. A imagem. Campinas: Papirus, 1993.

BAKHTIN, M. M. Estética da Criação Verbal. Tradução de Maria Emsantina Galvão G. Pereira. 2. ed. São Paulo: Fontes, 2003.

BROWN, J.A.C. Técnicas de persuasão. Rio de Janeiro: Ed. Zahar, 1971.

CHARAUDEAU P.Langage et Discours - Eléments de sémiolinguistique, Paris, Hachette, , 1983.

FAIRCLOUGH, N. Discurso e mudança social. Brasília: Editora Universidade de Brasília, 2001.

GONÇALVES, E. M. A palavra no mundo da imagem: uma reflexão sobre o ensino de Língua Portuguesa nos cursos de Publicidade e Propaganda. Revista Imes - Instituto Municipal de Ensino Superior de São Caetano do Sul. Ano XV, n. 43, p. 40-42, 1998.

HOOKS, B. Teaching to Transgress: Education as the practice of freedom. New York: Routledge, 1994.

JOLY, M.Introdução à Análise da Imagem, Lisboa, Ed. 70, 2007 — Digitalizado por SOUZA, R. 
REVISTA X, Curitiba, volume 14, n.3,211-226, 2019.

KOCH, I. G. V. Argumentação e linguagem. São Paulo: Cortez, 2002a.

O texto e a construção de sentidos. São Paulo: Contexto, 2002b.

KRESS, G.; VAN LEEUWEN, T. Reading images. The grammar of visual design. Londres; Nova York: Routledge, 1996.

- Multimodal Discourse: The Modes and Media of Contemporary Communication. Oxford UK: Oxford University Press, pp1-2, 2001.

KRESS, G. What is mode? In: JEWITT, C. (Org.). The Routledge Handbook of Multimodal Analysis. London: Routledge, 2009

MARCONI, M. A.; LAKATOS, E. M. Metodologia científica. São Paulo: Atlas, 2011

MARCUSCHI, L. A. Da fala para a escrita: atividades de retextualização. 8. ed. São Paulo, SP: Cortez, 2007.

Produção textual, análise de gêneros e compreensão. São Paulo: Parábola Editorial, 2008.

MARTINS, Z. Propaganda é isso aí. São Paulo: Ed. Atlas, 2004.

MILLER, C. Rhetorical Community: the cultural basis of genre. In FREEDMAN, A. \& MEDWAY, P. (Org.). Genreandthe New Rhetoric. London: Taylor \& Francis,1994, p. 67-78.

PREDEBON, J. Criatividade: abrindo o lado inovador da mente. 8. ed. São Paulo, SP: Pearson, 2013.

PENNYCOOK, A. Uma linguistica aplicada transgressiva. In.: MOITA LOPES, L. P. (Org.) Por uma Linguística Aplicada Indisciplinar. São Paulo: Parábola, 2016.

RAMALHO, V.;RESENDE, V.de M. Análise do discurso (para a) crítica: o texto como material de pesquisa. Campinas. SP: Pontes Editora,2011.

ROJO, R. Letramentos múltiplos, escola e inclusão social. São Paulo, SP: Parábola Editorial, 2009.

SANTAELlA, L. Semiótica aplicada. 3. ed. São Paulo, SP: Pioneira Thomson Learning, 2007.

VESTERGAARD, T.; SCHRODER, K. A linguagem da propaganda. Trad. João Alves dos Santos. São Paulo: M. Fontes, 2004. 